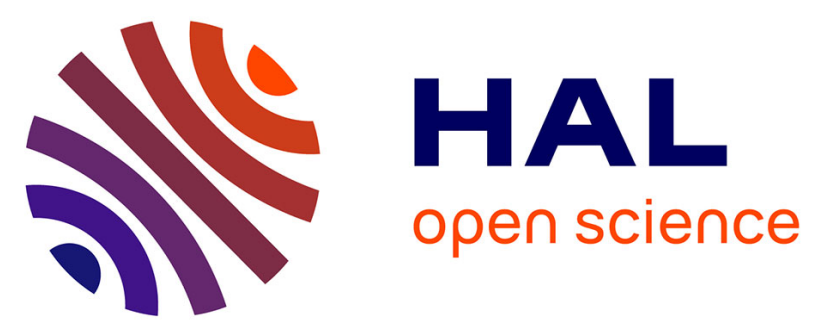

\title{
Modeling the Capillary Pressure for the Migration of the Liquid Phase in Granular Solid-Liquid-Vapor Systems: Application to the Control of the Composition Profile in W-Cu FGM Materials
}

\author{
Missiaen J.M., J.J. Raharijaona, F. Delannay
}

\section{To cite this version:}

Missiaen J.M., J.J. Raharijaona, F. Delannay. Modeling the Capillary Pressure for the Migration of the Liquid Phase in Granular Solid-Liquid-Vapor Systems: Application to the Control of the Composition Profile in W-Cu FGM Materials. Metallurgical and Materials Transactions A, 2016, 47 (11), pp.55695579. 10.1007/s11661-016-3702-5 . hal-01463944

\author{
HAL Id: hal-01463944 \\ https://hal.science/hal-01463944
}

Submitted on 15 May 2020

HAL is a multi-disciplinary open access archive for the deposit and dissemination of scientific research documents, whether they are published or not. The documents may come from teaching and research institutions in France or abroad, or from public or private research centers.
L'archive ouverte pluridisciplinaire HAL, est destinée au dépôt et à la diffusion de documents scientifiques de niveau recherche, publiés ou non, émanant des établissements d'enseignement et de recherche français ou étrangers, des laboratoires publics ou privés. 


\title{
Modeling the Capillary Pressure for the Migration of the Liquid Phase in Granular Solid-Liquid-Vapor Systems: Application to the Control of the Composition Profile in W-Cu FGM Materials
}

\author{
JEAN-MICHEL MISSIAEN, JEAN-JOËL RAHARIJAONA, \\ and FRANCIS DELANNAY
}

A model is developed to compute the capillary pressure for the migration of the liquid phase out or into a uniform solid-liquid-vapor system. The capillary pressure is defined as the reduction of the overall interface energy per volume increment of the transferred fluid phase. The model takes into account the particle size of the solid particle aggregate, the packing configuration (coordination number, porosity), the volume fractions of the different phases, and the values of the interface energies in the system. The model is used for analyzing the stability of the composition profile during processing of $\mathrm{W}-\mathrm{Cu}$ functionally graded materials combining a composition gradient with a particle size gradient. The migration pressure is computed with the model in two stages: (1) just after the melting of copper, i.e., when sintering and shape accommodation of the $\mathrm{W}$ particle aggregate can still be neglected and (2) at high temperature, when the system is close to full density with equilibrium particle shape. The model predicts well the different stages of liquid-phase migration observed experimentally.

\section{INTRODUCTION}

CAPILlary migration of the liquid-phase in a solid-liquid-vapor system is encountered in many applications involving granular materials. Infiltration of a liquid in a porous solid-vapor medium is one such application which concerns as well the permeation of water or oil in soils as the infiltration of a ceramic preform with a metallic liquid to process ceramic-metal composites. ${ }^{[1]}$ Liquid spreading also results from nonuniform liquid or porosity distribution in a granular material. This may occur as a liquid locally forms in a packed-bed reactor or in a powder compact undergoing liquid-phase sintering. This is also observed during heating multilayer powder compacts with a gradient in the liquid or porosity fraction. ${ }^{[2]}$ In drying operations, the reverse transfer occurs as gas replaces the liquid sequentially, first from largest pores and last from the

JEAN-MICHEL MISSIAEN, Professor, is with the Laboratoire de Science et Ingénierie des Matériaux et Procédés, CNRS, SIMAP, Université de Grenoble Alpes, 1130 rue de la piscine, BP 75, 38402, St Martin d'Héres, France. Contact e-mail: jean-michel.missiaen@ simap.grenoble-inp.fr FRANCIS DELANNAY, Professor Emeritus, is with the Institut de Mécanique, Materiaux et Génie Civil, IMAP, Université Catholique de Louvain, Place Sainte Barbe 2, 1348, Louvain-la-Neuve, Belgique. JEAN-JOËL RAHARIJAONA, Doctor-Engineer, formerly with the Laboratoire de Science et Ingénierie des Matériaux et Procédés, CNRS, SIMAP, Université de Grenoble Alpes, is now with the Material and Process Lab. - Aéroport International Marseille-Provence, Airbus Helicopter, 13725, Marignane, France. smallest pores. ${ }^{[3]}$ A similar situation occurs during the initial stage of drying of loose particle packings, such as silica gels, due to the high local capillary stresses. ${ }^{[4]}$ Migration or imbibition of liquid also takes place through sintering or desintering of the solid particle skeleton in dense solid-liquid materials with a gradient in the liquid composition or solid grain size.$^{[5,6]}$

The dynamics of migration is controlled by an equivalent pressure, which is commonly called the capillary pressure. For example, the capillary pressure $P_{\mathrm{C}}$ for liquid infiltration in a circular tube of radius $r$ is expressed as

$$
P_{\mathrm{C}}=\frac{2 \gamma_{\mathrm{LV}}}{r \cos \theta}
$$

where $\gamma_{L V}$ is the surface energy of the liquid, and $\theta$ is the contact angle. Infiltration or spreading of a liquid-phase into a porous granular medium is more difficult to analyze, due to the geometric complexity. Different authors have derived models based on the Laplace equation to compute the capillary pressure driving the infiltration of a liquid-phase into a porous granular medium, i.e., without solid-solid interfaces. ${ }^{[3,7]}$ Calculations take into account the evolution of the liquid surface around particle contacts in the particle packing. The capillary pressure for the migration of a liquid out of or into a solid-liquid system has been calculated using thermodynamic models of interfacial energy, by taking into account the contributions of solid-solid and solid-liquid interfaces. ${ }^{[6,8-10]}$ In another context, the capillary pressure for expulsion of the vapor-phase out of a solid-vapor granular system, also designated as 
"sintering stress" or "sintering pressure," has been determined by different authors from thermodynamic models of interfacial energy in a system undergoing sintering. ${ }^{[11-13]}$ The capillary pressure or "capillary force" driving particle rearrangement in the initial stage of liquid-phase sintering was also derived by analyzing the mechanical equilibrium of two particles connected with a pendular liquid ring. ${ }^{[14-16]}$

There have been few attempts to model the migration pressure of a liquid in the general case of a solid-liquid-vapor system containing solid-solid interfaces. This case is, however, of practical importance since microstructure or composition heterogeneity in the green body may induce migration pressure gradients and liquid-phase migration may occur during heating of a powder compact undergoing liquid-phase sintering. Heterogeneity may result from the powder mixing/forming step, but it can also be intentionally introduced to manufacture functionally graded materials, in which case control of liquid-phase migration is essential ${ }^{[2,17]}$ In a previous work, a model was developed to compute the capillary pressure (also called "migration pressure" or "imbibition pressure") for the migration of a liquid out or into a dense solid-liquid system. ${ }^{[10,18,19]}$ In this work, this model is adapted to compute the capillary pressure for the migration of the liquid-phase out or into a uniform solid-liquid-vapor system. The capillary pressure is defined as the reduction of the overall interface energy per volume increment of the transferred fluid phase. The context of application is then more general than for the previously proposed models. The present model accounts for the simple case of penetration in a circular tube (Eq. [1]) but more generally for the penetration of a liquid into the geometrically complex porosity of a powder compact or for various transport phenomena of a liquid-phase which may occur during the processing of solid-liquid-vapor granular systems (drying, infiltration, sintering...). The model takes into account the particle size of the solid particle aggregate, the packing configuration (coordination number, porosity), the volume fractions of the different phases, and the values of the interface energies. The basics of the model are presented in Sect. II, and the liquid migration pressure in a packing of spherical particles is calculated. In Sect. III, the model is applied to analyze experimental results for the migration of liquid copper during sintering $\mathrm{W}-\mathrm{Cu}$ powder compacts with a composition gradient. The computational details of the model are presented in the "Appendix."

\section{MODELING THE CAPILLARY PRESSURE IN A SOLID-LIQUID-VAPOR SYSTEM}

\section{A. Model}

The geometric model and the procedure used for the calculation of the capillary pressure in solid-liquid systems $^{[10]}$ is extended here to a three-phase solid-liquid-vapor system. The adapted system is modeled as consisting of an aggregate of solid particles immersed in the percolating porosity, where porosity is filled by the liquid-vapor mixture. The three phases are assumed at chemical equilibrium, i.e., driving forces for change result only from capillary forces. The system is divided into Voronoï cells enclosing each solid particle. Each cell thus consists of an assembly of $n_{\mathrm{C}}$ pyramidal prisms, $n_{\mathrm{C}}$ being the particle coordination number. The model substitutes these $n_{\mathrm{C}}$ prisms by $n_{\mathrm{C}}$ identical cones the revolution axis of which is the vector bounding the centers of gravity of two particles in contact (Figure 1). The opening angle $\beta$ at the apex of the cone is straightforwardly related to $n_{\mathrm{c}}$. In a previous work, this model was applied to two-phase systems to derive the capillary pressure for liquid migration in binary solid-liquid mixtures ${ }^{[5]}$ or the sintering stress in a solid-vapor system. ${ }^{[13]}$

The above model makes use of eight parameters: the average particle coordination number $n_{C}$; the particle volume $V_{\mathrm{P}}$; the density $\rho_{\mathrm{P}}=V_{\mathrm{P}} /\left(V_{\mathrm{P}}+V_{\mathrm{L}}+V_{\mathrm{V}}\right)$, or equivalently the porosity $u=1-\rho_{\mathrm{P}}$, of the solid particle skeleton-where $V_{\mathrm{L}}$ and $V_{\mathrm{V}}$ are the volumes of the liquid and vapor phases, respectively - in each cell; the volume fraction of liquid in the condensed mixture $v_{\mathrm{L}}=V_{\mathrm{L}} /\left(V_{\mathrm{P}}+V_{\mathrm{L}}\right)$, and the solid/vapor $\gamma_{\mathrm{Sv}}$, solid/solid $\gamma_{S S}$, solid/liquid $\gamma_{S L}$, and liquid/vapor $\gamma_{L V}$ are the corresponding interface energies. The dihedral angle is defined as $\Psi=2 \arccos \left(\gamma_{\mathrm{ss}} / 2 \gamma_{\mathrm{SL}}\right)$.

The representation of the system by cones of revolution implies that the percolating porosity is modeled as a set of channels with uniform cross section (like capillary pipes passing through the aggregate). Figure 2 sketches on a section of the cone the different cases which may exist depending on the value of the liquid volume fraction $v_{\mathrm{L}}$. Three successive stages may be distinguished, according to Reference 3.

1. The pendular stage, corresponding to localized liquid bridges between particles with a solid/liquid/vapor triple line at the particle surface. Pendular liquid bridges are connected to the remaining liquid only if the wetting angle is equal to zero and the solid surface is then covered with a liquid film ensuring the liquid continuity.

2. The funicular stage, starting when the liquid fraction exceeds the threshold at which the solid/ liquid/vapor triple line meets the boundary of the representative cone. The liquid phase then becomes fully interconnected throughout the porosity network. This would occur simultaneously and uniformly in the whole system in the case of monodisperse grain sizes, but progressively in the case of a pore size distribution. As long as some volume fraction of vapor is present, the porosity network is then divided in two parts: one part is completely filled with liquid (Figure 2(c)) whereas the liquid fraction in the other part remains equal to the threshold for the formation of a critical liquid pocket that completely wets the solid surface (Figure 2(b)). The liquid being continuous, the Laplace pressure arising from the curvature $\kappa_{\mathrm{LV}}$ of the liquid/vapor surface in pore channels still containing vapor is uniform (in the following, $\kappa_{\mathrm{LV}}$ always refers to the mean curvature defined as half 


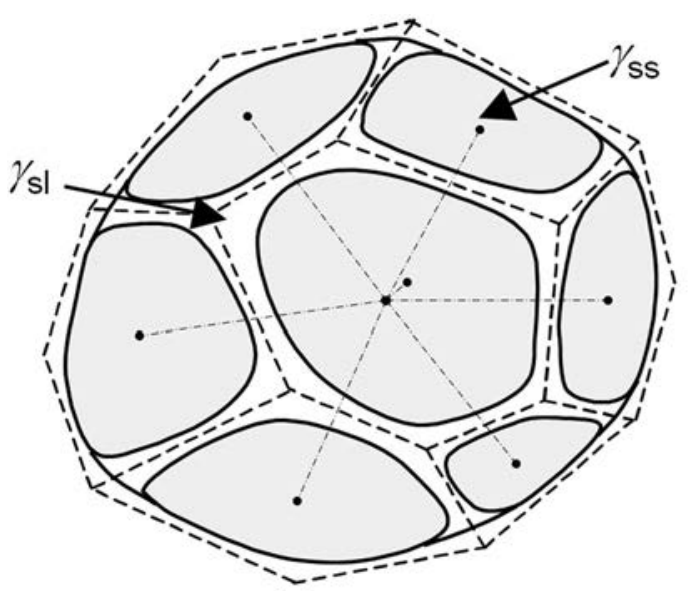

(a)

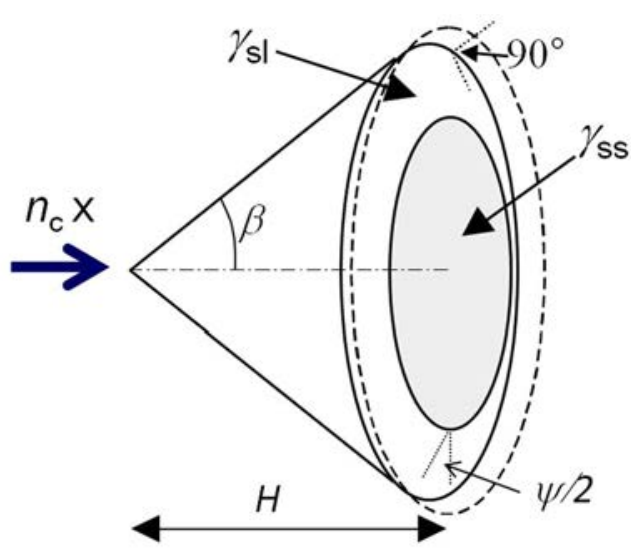

(b)

Fig. 1-Geometric model for the calculation of the capillary pressure. (a) Voronoi cell enclosing a solid particle; $(b)$ Approximation by $n_{\mathrm{C}}$ identical cones (adapted from Ref. [10] with permission from Elsevier).

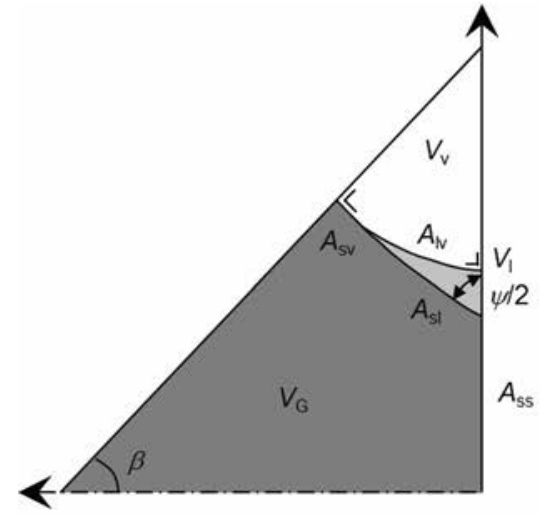

(a)

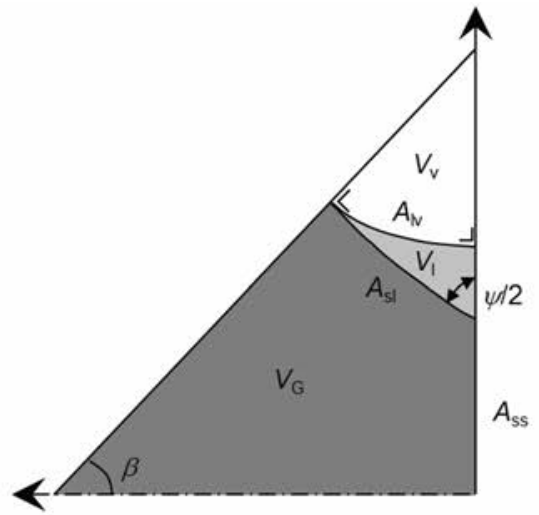

(b)

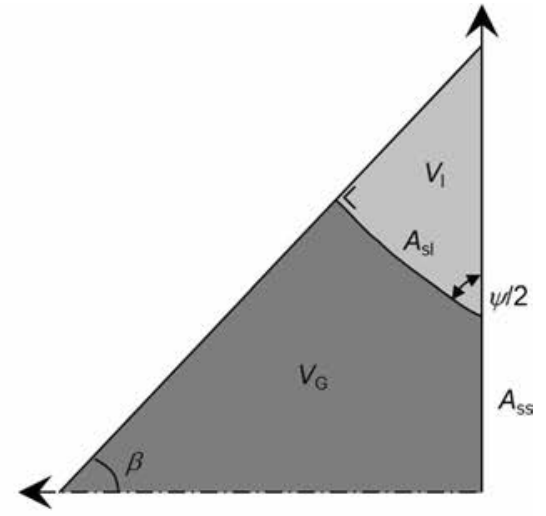

(c)

Fig. 2-The three local configurations to be considered for the solid-liquid-vapor system. (a) pendular stage; $(b, c)$ funicular stage; (c) alone $=$ final stage (reproduced from Ref. [20] with permission from Elsevier).

the sum of the two principal curvatures at a point, with curvature defined positive for a convex volume). In the case of capillary channels with uniform cross section, densification would, as long as part of porosity contains vapor, bring about a progressive increase of $\kappa_{\mathrm{LV}}$. Actually, for a 3D pore network with a pore size distribution, $\kappa_{\mathrm{LV}}$ decreases progressively during densification because the liquid progressively fills channels with larger cross section..$^{[3,21]}$

3. The final stage where the porosity is completely filled with liquid (Figure 2(c)). During this stage, densification of the solid skeleton yields a progressive exudation of the liquid out of the aggregate.

In general, the system can evolve by liquid migration, accommodation of grain shapes, and densification of the solid skeleton in such a way as to effect a decrease of the capillary energy

$$
F=\gamma_{\mathrm{SV}} A_{\mathrm{SV}}+\gamma_{\mathrm{SS}} A_{\mathrm{SS}}+\gamma_{\mathrm{SL}} A_{\mathrm{SL}}+\gamma_{\mathrm{LV}} A_{\mathrm{LV}}
$$

where $A_{\mathrm{SV}}, A_{\mathrm{SS}}, A_{\mathrm{SL}}$, and $A_{\mathrm{LV}}$ are the interface areas of the total solid/vapor, solid/solid, solid/liquid. and liquid/vapor, respectively. Only three of the four interface energies effectively play a role on the capillary equilibrium. Therefore, the total capillary energy will be scaled in this paper by the liquid-vapor interface energy, and only seven parameters control the evolution of the system.

In the absence of external forces, the work done for virtual change of the volume of liquid or vapor is equal to the change of the total energy. Hence, the driving force for the migration of a liquid phase or a vapor phase is defined from partial derivatives of the capillary energy $F$ with respect to the volume of the liquid or vapor. For example, during both the pendular stage and the funicular stage, the "capillary pressure" driving the migration of the liquid phase at fixed density (porosity) of the solid skeleton is defined as

$$
P_{\mathrm{C}}=-\left(\frac{\mathrm{d} F}{\mathrm{~d} V_{\mathrm{L}}}\right)_{n_{\mathrm{C}}, V_{\mathrm{P}}, u}
$$


whereas the sintering stress, i.e., the stress driving the densification of the solid skeleton by expulsion of the vapor phase is defined as

$$
P_{\mathrm{S}}=-\left(\frac{\mathrm{d} F}{\mathrm{~d} V_{\mathrm{V}}}\right)_{n_{\mathrm{C}}, V_{\mathrm{P}, v_{\mathrm{L}}}}
$$

Wakai et al ${ }^{[12]}$ have shown that Eq. [4] is fully equivalent to the calculation of sintering stress either from surface curvature or from the balance of the forces applied on any section through the aggregate. It must be noticed that definition [3] implies that the liquid migrates from positions where $P_{\mathrm{C}}$ is lower to positions where $P_{\mathrm{C}}$ is higher. Hence, although it is called a "pressure," $P_{\mathrm{C}}$ defined by [3] has the dimension of a stress, as well as $P_{\mathrm{S}}$ defined by [4]. During the final stage, the densification of the solid skeleton causes the expulsion of the liquid phase and the definitions [3] and [4] merge as

$$
P_{\mathrm{C}}=P_{\mathrm{S}}=-\left(\frac{\mathrm{d} F}{\mathrm{~d} V_{\mathrm{L}}}\right)_{n_{\mathrm{C}}, V_{\mathrm{P}}}
$$

Again in this case, the liquid tends to migrate from locations where $P_{\mathrm{C}}$ is lower to locations where $P_{\mathrm{C}}$ is higher.

The curvature $\kappa_{\mathrm{LV}}$ of the liquid-vapor interface is assumed to be uniform in the Voronoï cell, meaning that the timescale for homogenizing the local Laplace pressure in the liquid is always very small compared with the timescale for liquid- or vapor-phase migration considered in this paper. The curvature of the solid particle surface is also assumed uniform, which is more restrictive. Two types of migration pressure may be described under this hypothesis.

1. The pressure for the initial liquid migration by viscous flow in a packing of spherical particles: particle shape is considered to remain identical to the initial spherical shape because, during the initial stage, the rate for growth of grain boundaries and for accommodation of particle shapes is negligible with respect to the rate of viscous flow.

2. The pressure for liquid/vapor-phase suction or expulsion when the microstructure has sufficiently evolved to ensure sintering with quasi-equilibrium of grain boundaries and solid/liquid interfaces.

The computational details of the model are presented in the "Appendix."

\section{B. Example of the Use of the Model}

In order to provide a first insight into the phenomenon of liquid migration, we start with a presentation of computations, according to Eq. [3], of the migration pressure of a liquid in a particle packing at constant $u$, i.e., constant density of the particle skeleton. We assume that the particle rearrangement induced by the formation of the liquid phase is instantaneous as soon as the liquid volume fraction has reached equilibrium and that subsequent liquid migration causes no further particle rearrangement, i.e. no further increase of the average coordination $n_{\mathrm{C}}$. Moreover, the kinetics of grain boundary growth and particle shape accommodation is considered to be slow compared with liquid migration kinetics.

The calculation is performed for a packing of identical spherical particles in contact $\left(A_{\mathrm{SS}}=0\right)$ in which liquid is added at constant porosity fraction $u$ (i.e., $\left.\mathrm{d} V_{\mathrm{L}}=-\mathrm{d} V_{\mathrm{V}}\right)$. The coordination number $n_{\mathrm{C}}$ is taken to remain equal to 6 , the contact angle $\theta=0$, the dihedral angle $\Psi=0$ (spheres in contact). According to the representative cone model, the porosity of the particle packing is then $u=0.47 .^{[10]}$ The ratio of the solid-liquid interface energy, $\gamma_{\mathrm{SL}}$, to the surface energy of the liquid, $\gamma_{L V}$, is arbitrarily fixed at 1 . Since the solid surface is completely wetted by the liquid $(\theta=0)$, the actual solid surface energy, $\gamma_{\mathrm{SV}}$, and the effective solid surface energy, $\gamma_{\mathrm{SV}}{ }^{*}$, which are used in the calculation, verify

$$
\gamma_{\mathrm{SV}} \geq \gamma_{\mathrm{SL}}+\gamma_{\mathrm{LV}} \quad \text { and } \quad \gamma_{\mathrm{SV}}^{*}=\gamma_{\mathrm{SL}}+\gamma_{\mathrm{LV}}
$$

The following figures give the variations of the different interface areas $A_{\mathrm{SS}}, A_{\mathrm{SV}}, A_{\mathrm{SL}}$, and $A_{\mathrm{LV}}$ per grain (Figure 3 ), of the global interface energy $F$ per grain (Figure 4), and of the migration pressure $P_{\mathrm{C}}$ (Figure 5), as a function of the overall liquid volume fraction $v_{\mathrm{L}}$. Interface areas are normalized by $\left(V_{\mathrm{P}}\right)^{2 / 3}$, the total interface energy $F$ by $\gamma_{\mathrm{LV}}\left(V_{\mathrm{P}}\right)^{2 / 3}$, and the migration pressure $P_{C}$ by $\gamma_{\mathrm{LV}} /\left(V_{\mathrm{P}}\right)^{1 / 3}$.

Until the solid particles are completely wetted by the liquid, the solid-liquid area and the liquid-vapor area increase, while the solid-vapor area decreases as the volume fraction of liquid increases (Figure 3). The solid-solid interface area remains null since sintering of the solid skeleton is prohibited in the calculation. The global interface energy decreases with addition of liquid (Figure 4) and the migration pressure is thus constantly positive (Figure 5), i.e., the packing always tends to suck the liquid into the system. Under these conditions where the surface of the solid is fixed, $A_{\mathrm{SV}}+A_{\mathrm{SL}}$ is constant, and since the solid surfaces are completely wetted $(\theta=0)$, only the liquid-vapor interface plays a role on the interface energy variation and thus on the capillary pressure. The migration pressure tends to infinity at the $v_{\mathrm{L}}=0$ limit, where $\kappa_{\mathrm{LV}}$ also tends to infinity.

For a packing of spheres with $n_{\mathrm{C}}=6$, the transition between the pendular and funicular stage corresponds to $v_{\mathrm{L}} \approx 0.17$, and the pores become completely filled with liquid when $v_{\mathrm{L}} \geq 0.47$. During the progression of the liquid/vapor front along pore channels at $v_{\mathrm{L}}>0.17$, $A_{\mathrm{SS}}=A_{\mathrm{SV}}=0$, and $A_{\mathrm{SL}}$ remains constant, whereas $A_{\mathrm{LV}}$ decreases at a rate of $\mathrm{d} A_{\mathrm{LV}} / \mathrm{d} V_{\mathrm{L}}=2 \kappa_{\mathrm{LV}}\left(\kappa_{\mathrm{LV}}\right.$ is negative because the liquid volume is concave). This can be easily demonstrated as follows: if $A_{\mathrm{C}-\mathrm{S}}$ denotes the cross-sectional area of the channel at the position of the front, the decrease of capillary energy, $\gamma_{\mathrm{LV}} d A_{\mathrm{LV}}$, is equal to the work $\mathrm{d} W=2 \gamma_{\mathrm{LV}} A_{\mathrm{C}-\mathrm{S}} \kappa_{\mathrm{LV}} \mathrm{d} l$ done for a progression of the front on a distance $\mathrm{d} l=\mathrm{d} V_{\mathrm{L}} / A_{\mathrm{C}-\mathrm{S}}$. 


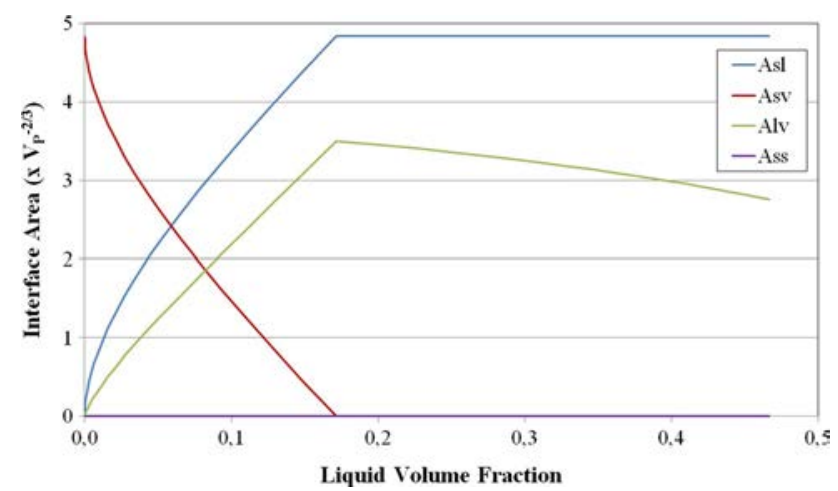

Fig. 3-Variation of interface areas $A_{\mathrm{SV}}, A_{\mathrm{SL}}, A_{\mathrm{LV}}$, and $A_{\mathrm{SS}}$ per grain as a function of the liquid volume fraction in a packing of spherical particles $\left(n_{\mathrm{C}}=6, \theta=0, \Psi=0, \gamma_{\mathrm{SL}} / \gamma_{\mathrm{LV}}=1\right)$.

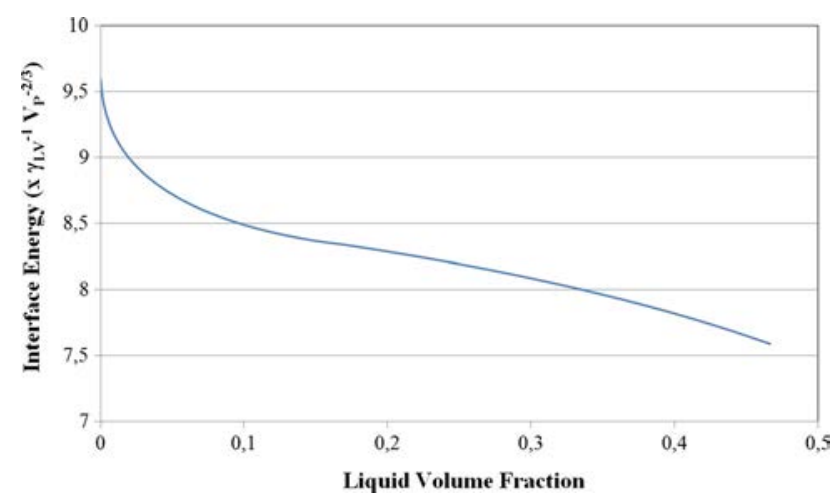

Fig. 4-Variation of the interface free energies $F$ per grain as a function of the liquid volume fraction in a packing of spherical particles $\left(n_{\mathrm{C}}=6, \theta=0, \Psi=0, \gamma_{\mathrm{SL}} / \gamma_{\mathrm{LV}}=1\right)$.

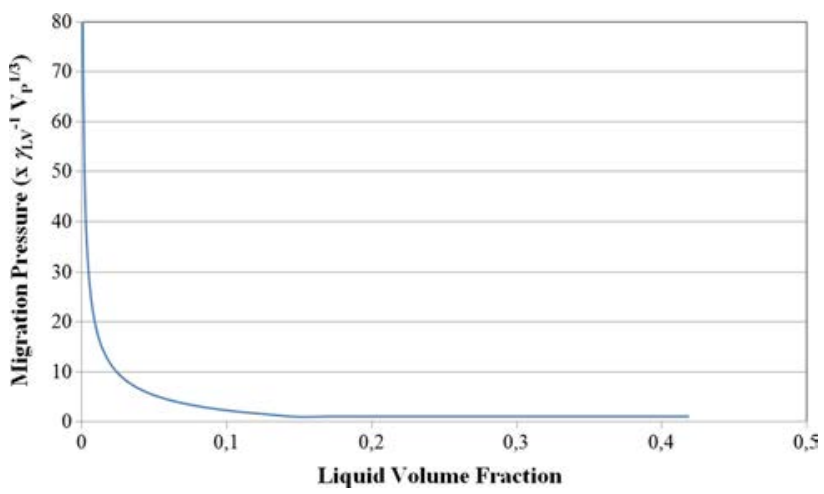

Fig. 5-Variation of the liquid migration pressures $P_{\mathrm{C}}$ as a function of the liquid volume fraction in a packing of spherical particles $\left(n_{\mathrm{C}}=6, \theta=0, \Psi=0, \gamma_{\mathrm{SL}} / \gamma_{\mathrm{LV}}=1\right)$.

As the model considers particles with single size, between which porosity channels present uniform cross section, $\kappa_{\mathrm{LV}}$ does not change during the funicular stage. This means that, during the range $0.17 \leq v_{\mathrm{L}} \leq 0.47, A_{\mathrm{LV}}$ decreases at a rate $2 \kappa_{\mathrm{LV}} V_{\mathrm{P}} /\left(1-v_{\mathrm{L}}\right)^{2}$ (Figure 3$)$, and $P_{\mathrm{C}}$ $\left(v_{\mathrm{L}}\right)$ remains equal to $-2 \gamma_{\mathrm{LV}} \kappa_{\mathrm{LV}}$ (Figure 5). Actually, in practical systems, the $3 \mathrm{D}$ arrangement of the porosity network and the distribution of particle sizes would bring about a progressive decrease of $\kappa_{\mathrm{LV}}$ during the gradual increase of the fraction of porosity filled by liquid..$^{[3,21]}$

\section{LIQUID-PHASE MIGRATION IN BI-LAYERS WITH DIFFERENT PARTICLE SIZES}

\section{A. Experimental Background}

In the following, the model is used for analyzing the stability of $\mathrm{W}-\mathrm{Cu}$ functionally graded materials combining a composition gradient with a particle size gradient. Such $\mathrm{W}-\mathrm{Cu}$ functionally graded materials are considered for the future nuclear fusion experiment ITER ${ }^{[22]} \mathrm{W}-\mathrm{Cu}$ powder mixtures were prepared with 10 and 20 wt pet $\mathrm{Cu}(19$ and 35 vol pet $\mathrm{Cu})$ and two W particle sizes of $0.2 \mu \mathrm{m}(\mathrm{F})$ and $0.5 \mu \mathrm{m}(\mathrm{C})$ (equivalent diameter from BET measurements). The samples with the four possible combinations of initial particle size and $\mathrm{Cu}$ fraction are referred as $10 \mathrm{~F}, 10 \mathrm{C}, 20 \mathrm{~F}$, and $20 \mathrm{C}$. Bi-layer powder compacts $10 \mathrm{~F} / 20 \mathrm{C}$ and $20 \mathrm{~F} / 10 \mathrm{C}$ were prepared by uniaxial die compaction of stacked layers of the different grades under $600 \mathrm{MPa}$. The particle size ratio $\mathrm{F} / \mathrm{C}$ in the bi-layers is thus $2 / 5$. The mass of powder in each layer was adjusted to get $2 \mathrm{~mm}$ thick final layers. The bi-layer compacts were sintered at $1653 \mathrm{~K}\left(1380{ }^{\circ} \mathrm{C}\right)$ for 2 hours under $\mathrm{He} / \mathrm{H} 2$ atmosphere in a SETARAM TMA92 dilatometer. For some experiments, the heating ramp was interrupted at $1403 \mathrm{~K}$ $\left(1130{ }^{\circ} \mathrm{C}\right)$ in order to allow characterization of the bi-layers just after completion of the melting of copper. Figure 6 is a SEM view of the microstructure of the W powder and of the fracture surface of sample $10 \mathrm{~F}$ after 2 hours sintering at $1653 \mathrm{~K}\left(1380^{\circ} \mathrm{C}\right)$. W particles have undergone significant grain growth during sintering and they are embedded in a continuous copper binder phase in the final material. The copper concentration profile in each layer was deduced from EDS measurement on polished cross sections of the samples (Figure 7). Dilatometric tests were also performed on the four homogeneous grades $10 \mathrm{~F}, 10 \mathrm{C}, 20 \mathrm{~F}$ and $20 \mathrm{C}$ in order to quantify their sintering behavior. The green density was deduced from initial geometric measurements and from the bulk theoretical density of each composition. The relative density (percent theoretical density TD) at different temperatures was computed from the green density and from the shrinkage measured in-situ in the dilatometric tests. These measurements allowed deduction of the porosity $u$ of aggregates of the homogeneous grades (Table I). Further details regarding the experiments can be found in References 2 and 22

For the $\mathrm{W}-\mathrm{Cu}$ system, the densification process is reduced to two stages, due to the negligible solubility of $\mathrm{W}$ in solid and liquid $\mathrm{Cu}^{[24,25]}$ : (1) a first stage of particle rearrangement and (2) a second stage of sintering of the solid W-skeleton. Solid-state sintering of the W-skeleton is then the active mechanism at $1653 \mathrm{~K}\left(1380{ }^{\circ} \mathrm{C}\right)$ with submicronic particles. ${ }^{[26]}$

Figure 7 shows that, immediately after formation of the liquid phase $\left[1403 \mathrm{~K}\left(1130{ }^{\circ} \mathrm{C}\right)\right]$, the liquid has migrated from the coarse to the fine grain layer, whereas 


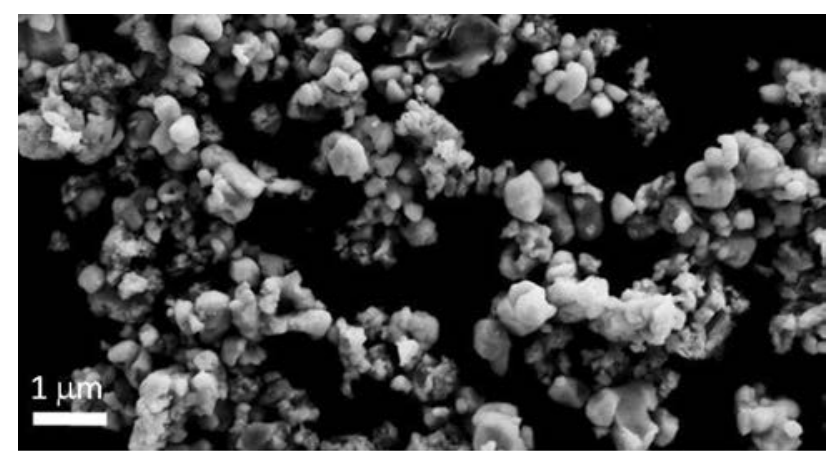

(a)

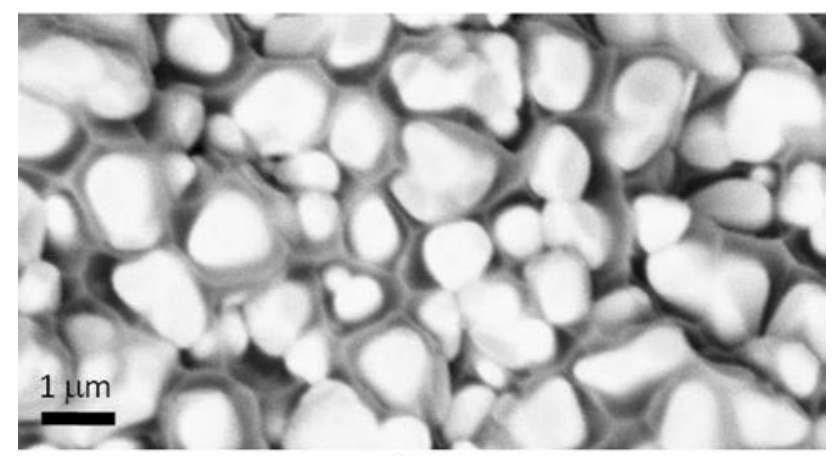

(b)

Fig. 6-SEM micrographs for comparison of W particles' morphologies and grain sizes $(a)$ in the initial $\mathrm{W}$ powder and $(b)$ in the $10 \mathrm{~F}$ $\mathrm{W}-\mathrm{Cu}$ sample after 2 -h sintering at $1653 \mathrm{~K}\left(1380^{\circ} \mathrm{C}\right)$ ((a) is reproduced from Ref. [23] with permission from Elsevier; (b) is reproduced from Ref. [25] with permission of Springer).

between $1653 \mathrm{~K}\left(1380{ }^{\circ} \mathrm{C}\right)$ and the end of the holding period of 2 hours at $1653 \mathrm{~K}\left(1380{ }^{\circ} \mathrm{C}\right)$, the liquid has been expulsed from the fine grain layer toward the coarse grain layer. In bi-layers $10 \mathrm{~F} / 20 \mathrm{C}$, in which the fine grain layer has initially a lower copper content, the composition profile has thus inverted twice during the heat treatment.

\section{B. Modeling Conditions}

Table II presents the interfacial energy values used in the computations. These values were obtained by Hodkin et al. from wetting and grain boundary grooving experiments, ${ }^{[27]}$ whereas the value of the surface energy near the melting point of copper $[\mathrm{T} \approx 1373 \mathrm{~K}$ $\left.\left(1100{ }^{\circ} \mathrm{C}\right)\right]$ is taken from a literature review. ${ }^{[28]}$ These data are considered as good approximations of surface and interface energies in the system in the $1373 \mathrm{~K}$ to $1773 \mathrm{~K}\left(1100{ }^{\circ} \mathrm{C}\right.$ to $\left.1500{ }^{\circ} \mathrm{C}\right)$ temperature range. They indicate a complete wetting of $W$ particles by the liquid $(\theta=0)$. The solid-vapor surface energy will thus be taken as $\gamma_{\mathrm{SV}}^{*}=\gamma_{\mathrm{SL}}+\gamma_{\mathrm{LV}}$ (Eq. [6]). We consider that, when $\theta=0$, the liquid can migrate along the liquid layer that covers the solid surface. The volume of the liquid meniscus can thus reach equilibrium even during the pendular stage.

\section{Liquid Partitioning Before the Formation of the Solid Skeleton}

The model is first applied to the bi-layers just after liquid formation, i.e., at $1403 \mathrm{~K}\left(1130^{\circ} \mathrm{C}\right)$. When this temperature is reached, the sintering of $W$ particles can be considered negligible. The shape of $W$ particles is thus assumed to have remained spherical, and the equivalent dihedral angle is $\Psi=0$. The calculations are made by choosing coordination values $n_{\mathrm{c}}$ such that the porosities $u$ calculated for the cone model were equal to porosity values measured at $1403 \mathrm{~K}\left(1130^{\circ} \mathrm{C}\right)$ on the homogeneous $\mathrm{W}-\mathrm{Cu}$ compacts $10 \mathrm{~F}, 10 \mathrm{C}, 20 \mathrm{~F}$, and $20 \mathrm{C}$ (Table I).

Figure 8 shows the migration pressure $P_{\mathrm{C}}$ predicted from this calculation as a function of the liquid volume fraction in the two parts of the W-Cu bi-layers $10 \mathrm{~F} / 20 \mathrm{C}$ (Figure $8(\mathrm{a})$ ) and $20 \mathrm{~F} / 10 \mathrm{C}$ (Figure $8(\mathrm{~b})$ ). As $P_{\mathrm{C}}$ scales with $1 / V_{\mathrm{P}}^{1 / 3}$, the liquid in layer $\mathrm{F}$ with fine grain size presents a larger migration pressure at given $v_{\mathrm{L}}$ than the liquid in layer $\mathrm{C}$ with coarser grain size. Hence, as indicated by the arrows, layer $\mathrm{F}$ will suck the liquid out of layer C. Liquid migration will stop when the capillary pressures in both layers equilibrate, which will occur either when layer $\mathrm{C}$ has reached the pendular stage or, if enough liquid is available, when layer $\mathrm{F}$ has reached the final stage. Accordingly, in bi-layers $10 \mathrm{~F} / 20 \mathrm{C}$, liquid migration is expected to invert the concentration profile with respect to the initial composition. On the contrary, in bi-layers $10 \mathrm{C} / 20 \mathrm{~F}$, liquid migration is expected to increase the concentration difference between the layers. The model predictions agree thus pretty well with experimental observations (Figure 7).

Comparison of the experimental composition profile to model predictions would need a more detailed experimental analysis of the $3 \mathrm{D}$ composition profile. Also the pressure variations during the funicular stage due to the 3D morphology of the pore network and due to the pore size distribution should be taken into account in the model. This is out of the scope of the present paper.

\section{Liquid Migration During Sintering of the Solid Skeleton}

The second computation is performed for layers in which particle shapes have evolved to equilibrium. Layers $\mathrm{C}$ and $\mathrm{F}$ are assumed to be in the configuration of the funicular or final stage, i.e., solid/vapor interfaces do not exist. In bi-layers, liquid migration at intermediate temperatures has increased the liquid fractions in layers $10 \mathrm{~F}$ and $20 \mathrm{~F}$ (Figure 7). According to Table I, the porosity values in homogeneous samples $10 \mathrm{~F}$ and $20 \mathrm{~F}$ after sintering at $1653 \mathrm{~K}\left(1380{ }^{\circ} \mathrm{C}\right)$ are more or less equal to the liquid volume fraction. Layers $10 \mathrm{~F}$ and $20 \mathrm{~F}$ in bi-layers can thus be considered as fully dense at the end of the sintering cycle. On the contrary, the liquid fraction in the coarse grain layers $(10 \mathrm{C}$ and 20C) is about $10 \mathrm{wt}$ pct $(19$ vol pct $\mathrm{Cu})$ in both bi-layers at the intermediate temperature of $1403 \mathrm{~K} \quad\left(1130{ }^{\circ} \mathrm{C}\right.$ ) (see Figure 7). Sintering in this layer may then be compared 
with the pure $10 \mathrm{C}$ sample, and densification is probably far from being completed at $1653 \mathrm{~K}\left(1380{ }^{\circ} \mathrm{C}\right)$ (Table I).

According to relations [2], [4], and [5], in the absence of solid/vapor interfaces, the sintering stress driving densification of the solid skeleton is the sum of the contributions of solid/solid, solid/liquid, and liquid/vapor interfaces. The contribution of liquid/vapor interface creates a pressure in the liquid. As pressure is the same everywhere in the liquid, only the contributions of

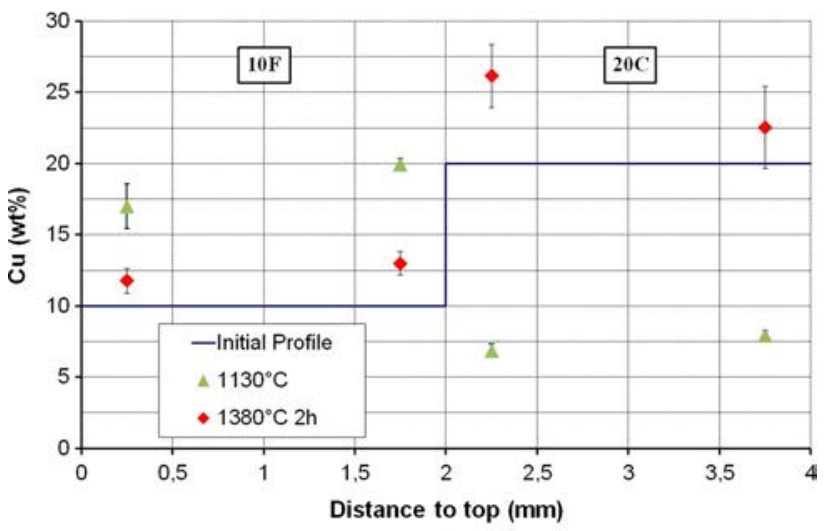

(a)

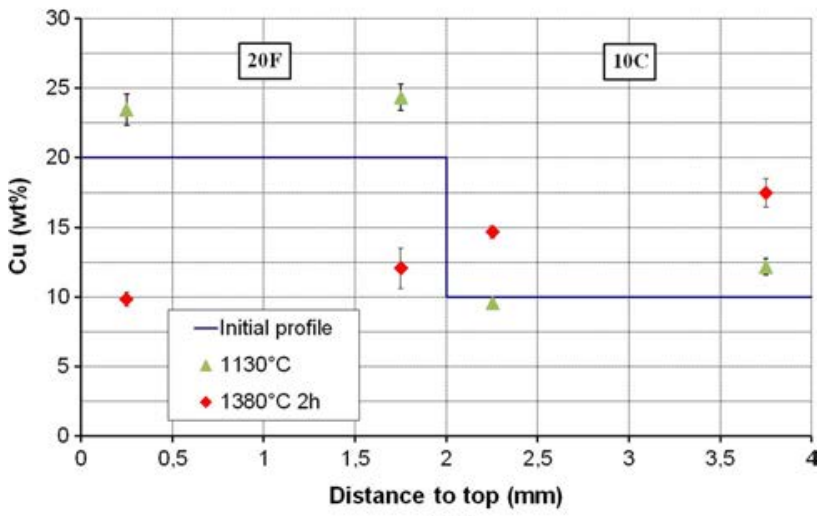

(b)

Fig. 7-Copper concentration profile in bi-layers W-Cu " $10 \mathrm{~F} / 20 \mathrm{C}$ " (a) and "20F/10C" (b) obtained from EDS measurement at $1403 \mathrm{~K}$ $\left(1130{ }^{\circ} \mathrm{C}\right)$ (interrupted) and after sintering at $1653 \mathrm{~K}\left(1380{ }^{\circ} \mathrm{C}\right)$ compared with the initial profile in the powder compact (adapted from Ref. [2] with permission from Wiley). solid/solid and solid/liquid interfaces cause a difference in sintering stresses in the two layers. According to definition [5], the sintering stress in the skeleton amounts to a capillary pressure in the liquid occupying the pores.

In principle, modeling of the contributions of solid/solid and solid/liquid interfaces in the sintering stress (or capillary pressure) would require taking proper account of the progressive increases of $n_{\mathrm{C}}$, and $V_{\mathrm{P}}$ during densification of the solid skeleton. In the present paper, $n_{\mathrm{C}}$ is assumed to remain constant at $n_{\mathrm{C}}=6$, and grain growth is supposed to not affect the particle size ratio, which is supposed to remain at $2 / 5$. The grain shape in each layer is supposed to evolve under quasi-equilibrium, which, using the data of Table II, means that $\Psi=116 \mathrm{deg}$.

Figure 9 shows the contributions of solid/solid and solid/liquid interfaces to the migration pressure $P_{\mathrm{C}}$ (or to the skeleton sintering stress) calculated according to relation 5 as a function of the porosity (i.e., as a function of the liquid volume fraction). For simplicity, the ordinate scale was defined using particle sizes equal to the initial sizes in mixtures $\mathrm{F}$ and $\mathrm{C}$. This definition of the ordinate scale does not affect the relative position of the curves as it is assumed that the size ratio remains $2 / 5$ during grain growth. $P_{\mathrm{C}}$ is negative, which means that the decrease of the capillary energy implies the expulsion of the liquid from the system. $P_{\mathrm{C}}$ is higher (i.e., less negative) for the layer $\mathrm{C}$ with the larger particle size, which means that the liquid will tend to migrate from layer $\mathrm{F}$ to layer $\mathrm{C}$. As explained above in this section, the pressure in the liquid due to the curvature of liquid/vapor interface adds a contribution to $P_{\mathrm{C}}$ in both layers, but the $P_{\mathrm{C}}$ difference between the layers is not affected. The trend is thus opposite to the trend observed in Figure 8 for the partitioning of liquid before the start of the sintering of the solid skeleton.

Following relation [5], the larger tendency of layer $\mathrm{F}$ to expel liquid is an image of the higher sintering stress for the solid skeleton. When sintering is governed by grain boundary diffusion, the densification rate varies as $V_{\mathrm{P}}^{-4 / 3[29]}$ The rate of the densification of the solid skeleton being larger in layer $\mathrm{F}$, the transfer of liquid to layer $\mathrm{C}$ will continue during the whole sintering process. Figure 9 shows that, as liquid is transferred from $\mathrm{F}$ to $\mathrm{C}$, the sintering stress difference between the two layers increases. No situation of stable equilibrium

Table I. Relative Density $\left(V_{\mathrm{P}}+V_{\mathrm{L}}\right) /\left(V_{\mathrm{P}}+V_{\mathrm{L}}+V_{\mathrm{V}}\right)=\rho_{\mathrm{P}} /\left(1-v_{\mathrm{L}}\right)$ (Percent Theoretical Density TD) and Total Porosity $u=1-\rho_{\mathrm{P}}=\left(V_{\mathrm{L}}+V_{\mathrm{V}}\right) /\left(V_{\mathrm{P}}+V_{\mathrm{L}}+V_{\mathrm{V}}\right)$ of the Particle Aggregate in the Four Homogeneous W-Cu Samples 10F, 10C, 20F, and $20 \mathrm{C}$ after Heating up to $1403 \mathrm{~K}\left(1130{ }^{\circ} \mathrm{C}\right)$ (Interrupted Sintering Process) and after Sintering for $2 \mathrm{~h}$ at $1653 \mathrm{~K}\left(1380{ }^{\circ} \mathrm{C}\right)$

\begin{tabular}{|c|c|c|c|c|c|c|c|c|}
\hline \multirow[b]{2}{*}{ Sample } & \multicolumn{2}{|c|}{$10 \mathrm{~F}$} & \multicolumn{2}{|c|}{$10 \mathrm{C}$} & \multicolumn{2}{|c|}{$20 \mathrm{~F}$} & \multicolumn{2}{|c|}{$20 \mathrm{C}$} \\
\hline & PctTD & $u$ & PctTD & $u$ & PctTD & $u$ & PctTD & $u$ \\
\hline $1403 \mathrm{~K}\left(1130^{\circ} \mathrm{C}\right)$ & 60.7 & 51.0 & 65.7 & 47.0 & 86.2 & 44.0 & 69.2 & 55.0 \\
\hline $1653 \mathrm{~K}\left(1380^{\circ} \mathrm{C}\right)(2 \mathrm{~h})$ & 97.9 & 21.0 & 81.8 & 34.0 & 96.9 & 37.0 & 95.4 & 38.0 \\
\hline
\end{tabular}

Table II. Surface and Interface Energies in the W-Cu System (From Refs. 27,28)

\begin{tabular}{llll}
\hline$\gamma_{\mathrm{LV}}\left(\mathrm{J} \mathrm{m}^{-2}\right)=1.15$ & $\gamma_{\mathrm{SL}}\left(\mathrm{J} \mathrm{m}^{-2}\right)=1.02$ & $\gamma_{\mathrm{SS}}\left(\mathrm{J} \mathrm{m}^{-2}\right)=1.08$ & $\gamma_{\mathrm{SV}}\left(\mathrm{J} \mathrm{m}^{-2}\right)=2.83$ \\
\hline
\end{tabular}




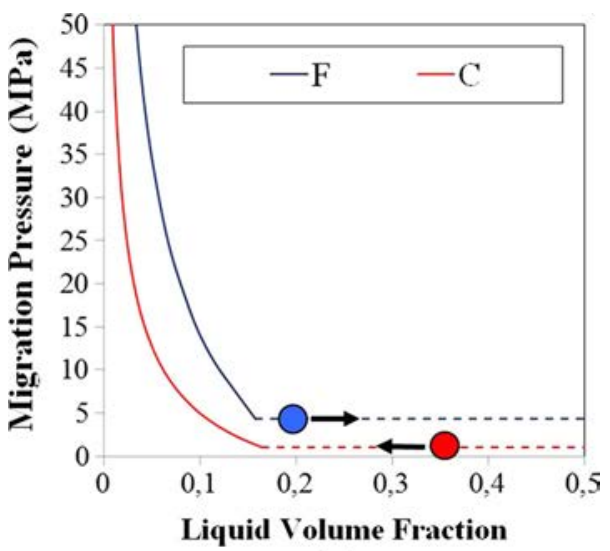

(a)

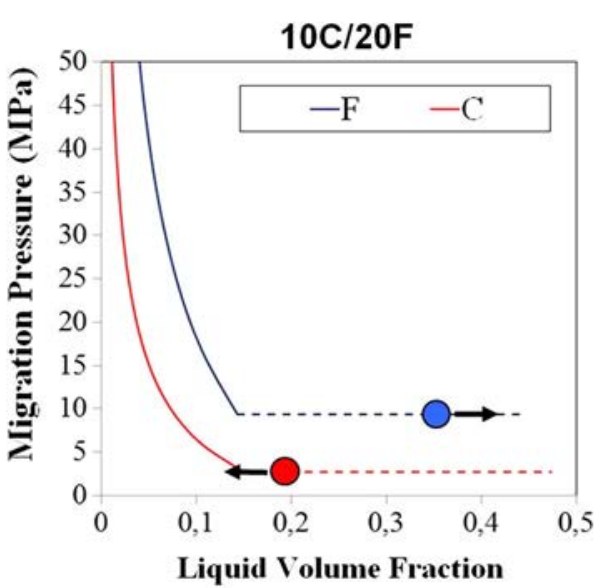

(b)

Fig. 8-Variation of the liquid migration pressure as a function of the liquid volume fraction calculated at $1403 \mathrm{~K}\left(1130^{\circ} \mathrm{C}\right)$ in $\mathrm{W}-\mathrm{Cu}$ bi-layers $10 \mathrm{~F} / 20 \mathrm{C}(a)$ and $20 \mathrm{~F} / 10 \mathrm{C}(b)$. The model parameters are $\theta=0, \Psi=0$ together with values of the porosity presented in Table I. The arrows indicate the direction of liquid migration.

can thus be reached. The distribution of the liquid phase at the end of the sintering period is thus a function only of the kinetics of sintering and of the conditions of heat treatment.

\section{CONCLUSION}

A model is proposed to compute the capillary pressure for liquid-phase migration in a uniform solid-liquid-vapor system. The capillary pressure is deduced from the variation of the overall interface energy in the system. The model is applied to predict liquid migration in $\mathrm{W}-\mathrm{Cu}$ functionally graded materials combining a composition gradient with a particle size gradient. A first migration occurs after melting of copper, by viscous flow from the coarse particle layer to the fine particle layer. A second migration takes place at higher temperature, as sintering of the particle skeleton in the fine particle layer expulses the liquid phase into the coarse particle layer. The model predictions are consistent with experimental observations made on the $\mathrm{W}-\mathrm{Cu}$ graded materials.

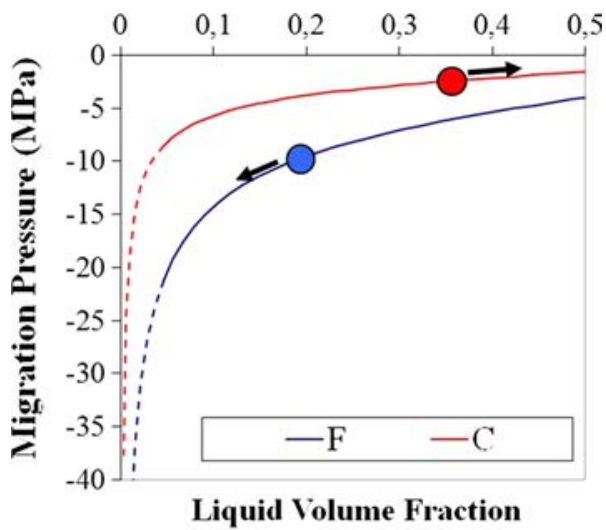

(a)

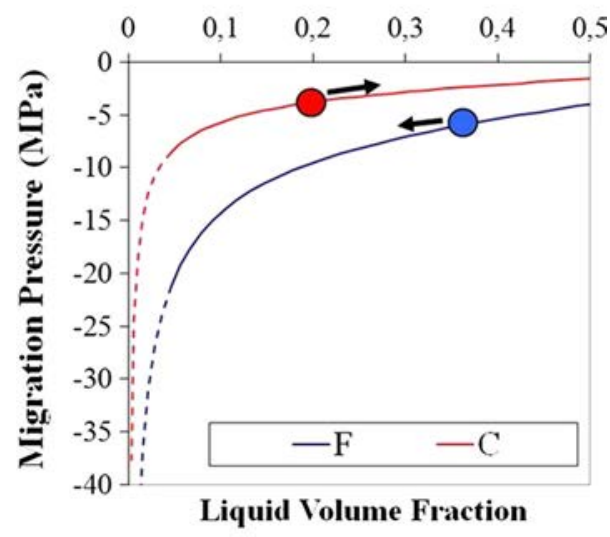

(b)

Fig. 9-Variation, in fully dense bi-layers $10 \mathrm{~F} / 20 \mathrm{C}(a)$ and $20 \mathrm{~F}-10 \mathrm{C}$ (b), of the contributions of solid/solid and solid/liquid interfaces to the liquid migration pressure $P_{\mathrm{C}}$ as a function of the porosity (or liquid volume fraction in filled pores) $(\Psi=116 \mathrm{deg})$. The direction of liquid migration is indicated by arrows.

\section{ACKNOWLEDGMENTS}

This work was carried out with the support of the EFDA (European Fusion Development Agreement) and the European Union under the Association EURATOM/CEA entity. The authors also wish to thank the Eurotungstene company (Eramet group) for material supply and technical support.

\section{APPENDIX: GEOMETRIC CALCULATIONS}

As shown in Figure 10, let us consider an orthogonal system of axes for which the origin is at the center of the cone basis, with coordinate axis $X$ parallel to the basis, and $Y$ pointing to the cone apex. The half-angle at the cone apex $\beta$ simply derives from the average coordination number $n_{\mathrm{C}}$ of the particles:

$$
\beta=\arccos \left(1-\frac{2}{n_{\mathrm{c}}}\right)
$$

The volume of the cone is given by the expression: 


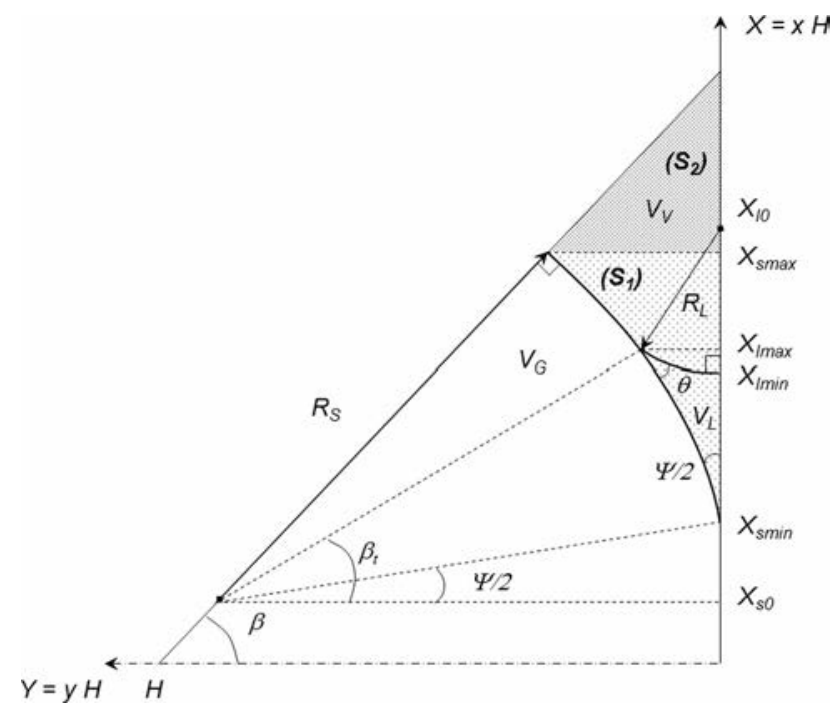

Fig. 10-Plane section through the cone axis of Fig. 1 showing the profile of the solid particle surface and of the liquid-vapor surface during the pendular stage.

$$
V_{\text {cone }}=\frac{V_{\mathrm{P}}}{n_{\mathrm{c}}(1-u)}
$$

The curves denoted $Y_{\mathrm{S}}(X)$ and $Y_{\mathrm{L}}(X)$ are, respectively, the profiles of the solid/porosity interface and of the liquid/vapor interface intersected by plane $(X, Y)$. The curve $Y_{\mathrm{S}}(X)$ will be considered as divided into two parts: the part $Y_{\mathrm{SL}}(X)$ expanding from the cone basis to the solid/liquid/vapor triple line represents the trace of solid/liquid interface whereas the part $Y_{\mathrm{SV}}(X)$ expanding from the solid/liquid/vapor triple line to the lateral surface of the cone represents the trace of the solid/vapor interface. The angle $\beta_{\mathrm{t}}<\beta$ locates the position of the triple line in the plane section, which is fixed for a given set of input parameters. $\beta_{\mathrm{t}}$ tends to $\beta$ as the liquid volume fraction reaches a critical value where the liquid menisci between adjacent particle contacts merge. This point will be addressed at the end of this appendix. At each point along the $Y_{\mathrm{S}}(X)$ or $Y_{\mathrm{L}}(X)$ curve, the radius of curvature is one of the two principal radii of curvature of the interface. This radius, which will be denoted $R_{\text {in plane, }}$, is defined positive when the center of curvature is on the solid side of the interface for $Y_{\mathrm{S}}(X)$ or on the liquid side of the interface for $Y_{\mathrm{L}}(X)$ and negative otherwise. For example, in the case presented in

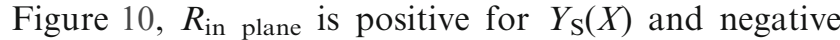
for $Y_{\mathrm{L}}(X)$. As interfaces are generated by the revolution of the corresponding $Y(\mathrm{X})$ curve around the cone axis, the second principal radius of curvature, denoted $R_{\text {out of plane, is always positive. }}$

The porosity volume fraction $u$ and the different interface areas $A_{\mathrm{SV}}, A_{\mathrm{SL}}$, and $A_{\mathrm{LV}}$ per grain are univocally determined by curves $Y_{\mathrm{S}}(X)$ and $Y_{\mathrm{L}}(X)$. For this purpose, it is convenient to convert $X$ and $Y(X)$ into nondimensional variables:

$$
x=\frac{X}{H}
$$

$$
\begin{aligned}
& y_{\mathrm{S}}(x)=\frac{Y_{\mathrm{S}}(X)}{H} \\
& y_{\mathrm{L}}(x)=\frac{Y_{\mathrm{L}}(X)}{H}
\end{aligned}
$$

The ranges for $x$ and $y(x)$ are thus $0 \leq x \leq \tan \beta$ and $0 \leq y(x) \leq 1$. The coordinates of the three points at the extremities of curves $Y_{\mathrm{SL}}(x)$ and $Y_{\mathrm{SV}}(x)$ are denoted $\left(x_{\text {Smin }}, 0\right), \quad\left(x_{\text {Lmax }}, y_{\text {Lmax }}\right)$, and $\left(x_{\text {Smax }}, y_{\text {Smax }}\right)$. In Figure 10, the surface representing porosity is divided in two parts, denoted $S_{1}$ and $S_{2}$. The volume of porosity is the volume created by the revolution of these surfaces around the cone axis. The corresponding two volumes, denoted $V_{1}$ and $V_{2}$, respectively, are expressed as

$$
V_{1}=2 \pi H^{3} \int_{x_{\mathrm{S} \min }}^{x_{\mathrm{Smax}}} x y_{\mathrm{S}}(x) \mathrm{d} x
$$

and

$$
V_{2}=2 \pi H^{3}\left(x_{\text {Smax }}+\frac{\tan \beta-\mathrm{x}_{\text {Smax }}}{3}\right) \frac{\left(\tan \beta-\mathrm{x}_{\text {Smax }}\right)^{2}}{2 \tan \beta}
$$

The porosity volume fraction is thus

$$
\begin{aligned}
u= & \frac{6}{\tan ^{2} \beta}\left[\int_{x_{\text {Smin }}}^{x_{\text {Smax }}} x y_{S}(x) \mathrm{d} x+\left(x_{\text {Smax }}+\frac{\tan \beta-x_{\text {Smax }}}{3}\right)\right. \\
& \left.\times \frac{\left(\tan \beta-x_{\text {Smax }}\right)^{2}}{2 \tan \beta}\right]
\end{aligned}
$$

The liquid volume can be calculated in the same way, with distinction between situations where the meniscus is concave or convex. If $\left(\beta_{t}+\theta\right)<\pi / 2$ (concave menisci), then

$$
V_{\mathrm{L}}=2 \pi n_{\mathrm{C}} H^{3}\left(\int_{x_{\mathrm{S} \min }}^{x_{\mathrm{L} \min }} x y_{\mathrm{S}}(x) \mathrm{d} x+\int_{x_{\mathrm{Lmin}}}^{x_{\mathrm{Lmax}}} x\left(y_{\mathrm{S}}(x)-y_{\mathrm{L}}(x)\right) \mathrm{d} x\right) \text {, }
$$

whereas if $\left(\beta_{t}+\theta\right)>\pi / 2$ (convex menisci), then

$$
V_{\mathrm{L}}=2 \pi n_{\mathrm{C}} H^{3}\left(\int_{x_{\mathrm{S} \min }}^{x_{\mathrm{Lmax}}} x y_{\mathrm{S}}(x) \mathrm{d} x+\int_{x_{\mathrm{Lmax}}}^{x_{\mathrm{Lmin}}} x y_{\mathrm{L}}(x) \mathrm{d} x\right),
$$

and the liquid volume fraction in the condensed mixture

$$
v_{\mathrm{L}}=V_{\mathrm{L}} /\left(V_{\mathrm{G}}+V_{\mathrm{L}}\right)
$$

is deduced.

The solid/liquid, solid/vapor, and liquid/vapor interface areas are created by a revolution of the curves $Y_{\mathrm{SL}}(X), Y_{\mathrm{SV}}(X)$, and $Y_{\mathrm{LV}}(X)$. respectively, around the 
cone axis. Denoting $H d s$ an increment of length along the curve, the interface area per grain $A_{\mathrm{SL}}, A_{\mathrm{SV}}$, and $A_{\mathrm{LV}}$ is written as

$$
\begin{aligned}
& \left.A_{\mathrm{SL}}=n_{\mathrm{c}} H^{2} 2 \pi \int_{\left(x_{\mathrm{S} \min }, y_{\mathrm{S} \min }\right)}^{\left(x_{\mathrm{Lmax}}, y_{\mathrm{Lmax}}\right)} x \mathrm{~d} s_{\mathrm{SL}}\right) \\
& \left.A_{\mathrm{SV}}=n_{\mathrm{c}} H^{2} 2 \pi \quad \int_{\left(x_{\mathrm{L} \max }, y_{\mathrm{L} \max }\right)}^{\left(x_{\mathrm{S} \max }, y_{\mathrm{S} \max }\right)} x \mathrm{~d} s_{\mathrm{SV}}\right) \\
& \left.A_{\mathrm{LV}}=n_{\mathrm{c}} H^{2} 2 \pi \int_{\left(x_{\mathrm{L} \min }, y_{\mathrm{L} \min }\right)}^{\left(x_{\mathrm{Lmax}}, y_{\mathrm{L} \max }\right)} x \mathrm{~d} s_{\mathrm{LV}}\right)
\end{aligned}
$$

Finally, as $H x_{\text {Smin }}$ is the radius of the circle circumscribing the solid/solid interface, the solid/solid interface area $A_{\mathrm{SS}}$ per grain is simply

$$
A_{\mathrm{SS}}=\frac{1}{2} n_{\mathrm{c}} H^{2} \pi x_{\mathrm{Smin}}^{2}
$$

The family of axisymmetric surfaces with uniform curvature is called the Delaunay surfaces, and the curves generating these surfaces are called the Delaunay roulettes. $^{[30]}$ Although the problem can be solved exactly, it is tempting to approximate the curves $Y_{\mathrm{S}}(X)$ and $Y_{\mathrm{L}}(X)$ by two arcs of circle. The total curvature $1 / R_{\text {tot }}$ is then not uniform because the out of plane

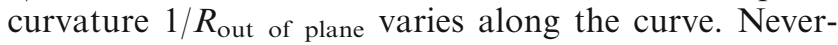
theless, it has been shown that this approximation does not bring about a large overestimation of the capillary energy in the case of a solid-liquid system. ${ }^{[18]}$

Equation of the surface profiles and boundary conditions for the calculations of the different volumes and areas must then be obtained. Let us denote $R_{\mathrm{S}}=r_{\mathrm{S}} H$ and $R_{\mathrm{L}}=r_{\mathrm{L}} H$ the radii of the arcs of circle representing the profiles of the solid/porosity and liquid/vapor interface, respectively. $r_{\mathrm{S}}$ and $r_{\mathrm{L}}$ are taken negative when the center of curvature of the profile is directed toward the exterior of the corresponding phase. By symmetry, the solid/porosity interface meets at $90 \mathrm{deg}$ the lateral surfaces of the cone. It follows that the coordinates $\left(x_{\mathrm{S} 0}, y_{\mathrm{S} 0}\right)$ of the in-plane center of curvature of this interface are

$$
x_{\mathrm{S} 0}=\tan \beta\left(1-r_{\mathrm{S}} \cos \frac{\psi}{2}\right)
$$

and

$$
y_{\mathrm{S} 0}=r_{\mathrm{S}} \cos \frac{\psi}{2}
$$

The function $y_{\mathrm{S}}(x)$ then is written as

$$
y_{\mathrm{S}}(x)=|| y_{\mathrm{S} 0}\left|-\sqrt{r_{\mathrm{S}}^{2}-\left(x-x_{\mathrm{S} 0}\right)^{2}}\right|
$$

In the same way, the liquid/vapor interface meets at 90 deg the grain boundary plane, and the liquid content is parameterized either by the angle $\beta_{\mathrm{t}}$ or by the coordinate $x_{\text {Lmax }}$ locating the solid/liquid/vapor triple line in the plane section (see Figure 10):

$$
\sin \left(\beta_{\mathrm{t}}\right)=\frac{x_{L \max }-x_{S 0}}{r_{\mathrm{S}}}
$$

It follows that the coordinates $\left(x_{\mathrm{L} 0}, y_{\mathrm{L} 0}\right)$ of the in-plane center of curvature of this interface are

$$
x_{\mathrm{L} 0}=x_{\mathrm{S} 0}+r_{\mathrm{S}} \sin \beta_{\mathrm{t}}-r_{\mathrm{L}} \sin \left(\beta_{\mathrm{t}}+\theta\right)
$$

and

$$
y_{\mathrm{L} 0}=0
$$

The function $y_{\mathrm{L}}(x)$ is then written as

$$
y_{\mathrm{L}}(x)=\sqrt{r_{\mathrm{L}}^{2}-\left(x-x_{\mathrm{L} 0}\right)^{2}}
$$

and the coordinates of the limits of the corresponding profile are given by

$$
\begin{gathered}
x_{\mathrm{Smin}}=x_{\mathrm{S} 0}+r_{\mathrm{S}} \sin \frac{\psi}{2} \\
x_{\mathrm{Lmin}}=x_{\mathrm{L} 0}+r_{\mathrm{L}} \\
x_{\mathrm{S} \max }=x_{\mathrm{S} 0}+r_{\mathrm{S}} \sin \beta
\end{gathered}
$$

Moreover, $r_{\mathrm{S}}$ and $r_{\mathrm{L}}$ are related by

$$
r_{\mathrm{S}} \cos \beta_{\mathrm{t}}-r_{\mathrm{L}} \cos \left(\beta_{\mathrm{t}}+\theta\right)=r_{\mathrm{S}} \cos \frac{\psi}{2}
$$

At the limit of the pendular stage, when $\beta_{\mathrm{t}}=\beta$, a critical situation where adjacent liquid menisci merge is encountered. The in-plane center of curvature of the liquid-vapor interface is then transferred to the intersection between the cone and the boundary plane. This leads to a discontinuity in the position of the center and in the radius of curvature:

$$
x_{\mathrm{L} 0}=\tan (\beta)
$$

$$
y_{\mathrm{L} 0}=0
$$

$$
\text { and } r_{\mathrm{L}}=-\left(x_{\mathrm{L} 0}-x_{\mathrm{Lmax}}\right) / \sin (\beta)
$$

The porosity volume fraction $u$ and the interface areas $A_{\mathrm{SL}}, A_{\mathrm{SV}}, A_{\mathrm{LV}}$, and $A_{\mathrm{SS}}$ per grain are obtained by numerical calculations from relations [14] and [19]. The interface energy $F$ per grain is deduced from Eq. [2].

\section{REFERENCES}

1. A. Mortensen: in Comprehensive Composite Materials, A. Kelly, C. Zweben eds., Pergamon, Oxford, 2000, pp. 521-54. 
2. J.-J. Raharijaona, J.-M. Missiaen, and R. Mitteau: Ceram. Trans., 2010, vol. 209, pp. 321-31.

3. K. Lappalainen, M. Manninen, V. Alopaeus, J. Aittamaa, and J. Dodds: Transp. Porous Media, 2009, vol. 77 (1), pp. 17-40.

4. A. Bisson, A. Rigacci, D. Lecomte, E. Rodier, and P. Achard: Dry Technol, 2003, vol. 21 (4), pp. 593-628.

5. C. Colin, V. Guipont, and F. Delannay: Metall. Trans. A, 2006, vol. 38 , pp. $150-58$.

6. A.F. Lisovsky: Int. J. Heat Mass Transf., 1990, vol. 33 (8), pp. 1599-1603.

7. J.A. Dodds and P. Srivastava: Part Part Syst Charact, 2006, vol. 23 (1), pp. 29-39.

8. H.H. Park, S.J. Cho, and D.N. Yoon: Metall. Trans., 1984, vol. 15A, pp. 1075-80.

9. H.H. Park, S.J.L. Kang, and D.N. Yoon: Metall. Trans., 1986, vol. 17A, pp. 325-30.

10. F. Delannay, D. Pardoen, and C. Colin: Acta Mater., 2005, vol. 53 (6), pp. 1655-64.

11. L.C. De Jonghe and M.N. Rahaman: Acta Metall., 1988, vol. 36 (1), pp. 223-29.

12. F. Wakai, Y. Shinoda, and T. Akatsu: Acta Mater., 2004, vol. 52 (19), pp. 5621-31.

13. F. Delannay and J.-M. Missiaen: Acta Mater., 2009, vol. 57 (2), pp. $420-31$.

14. R.B. Heady and J.W. Cahn: Metall. Trans., 1970, vol. 1A, pp. 185-89.

15. W.J. Huppmann and H. Riegger: Acta Metall. Mater., 1975, vol. 23 , pp. $965-71$.
16. Z.S. Nikolic and F. Wakai: Math. Comput. Modell., 2012, vol. 55, pp. $1251-62$.

17. J.L. Johnson, R.M. German: in Proceedings of 16th Plansee Seminar 2, 116-129, G. Kneringer, R. Rödhammer, H. Wildner eds., Reutte, Plansee (2005).

18. F. Delannay: Philosophical Magazine, 2005, vol. 85 (31), pp. 3719-33.

19. F. Delannay and C. Colin: Mater. Sci. Eng. A, 2008, vol. 495 (1-2), pp. 236-43.

20. F. Delannay: Surf. Sci., 2016, vol. 648, pp. 262-70.

21. J. Svoboda, H. Riedel, and R. Gaebel: Acta Mater., 1996, vol. 44, p. 3215.

22. O. Ozer, J.-M. Missiaen, S. Lay, and R. Mitteau: Mater. Sci. Eng. $A, 2007$, vols. 460-461, pp. 525-31.

23. F. Delannay and J.M. Missiaen: Acta Mater., 2016, vol. 106, pp. $22-31$.

24. J. Johnson, J. Brezovsky, and R. German: Metall. Mater. Trans., 2005, vol. 36A, pp. 1557-65.

25. J.-J. Raharijaona, J.-M. Missiaen, and D. Bouvard: Metall. Mater. Trans., 2011, vol. 42A, pp. 2411-19.

26. J. Johnson, J. Brezovsky, and R. German: Metall. Mater. Trans., 2005, vol. 36A, pp. 2807-14.

27. E.N. Hodkin, M.G. Nicholas, and D.M. Poole: J. Less-Common Met., 1970, vol. 20, pp. 93-103.

28. B.J. Keene: Intern. Mater. Rev., 1993, vol. 38 (4), pp. 157-92.

29. H. Riedel, H. Zipse, and J. Svoboda: Acta Metall. Mater., 1994, vol. 42, pp. 445-52.

30. C.H. Delaunay: J. Math. Pures et Appl., 1841, pp. 309-14. 